\title{
Effect of Electron and Proton on Hydrogen-Bonded Imidazole Chains
}

\author{
Shihai Yan \\ College of Chemistry and Pharmaceutical Sciences, Qingdao Agricultural University, Qingdao, 266109, China
}

*Corresponding Author: Shihai Yan, College of Chemistry and Pharmaceutical Sciences, Qingdao Agricultural University, Qingdao, 266109, China

\begin{abstract}
Hydrogen bonded imidazole systems have attracted extensive efforts because they play a key role in proton conduction and biological processes. Proton transfer along the hydrogen-bonded imidazole chain is elucidated with a special emphasis on electronic and protonic effect. The chain length reduces upon both electron and proton gain or loss. The flexibility of water and ammonia mediated chain is larger as compared with that of imidazole mediated system. The typical IR spectra of NH...N hydrogen bonds shift distinctly with electron and proton variation. NMR chemical shifts and spin-spin coupling constants are employed as the criterions in judging whether the proton is transferred or not. The initial step for the conduction mechanism of imidazole chain should not be oxidation. It is expected that the ammonia mediated chain is a better conductive material as compared with water and imidazole mediated systems.
\end{abstract}

Keywords: Hydrogen bond; Proton transfer; Imidazole; Chemical shift; Potential energy surface.

\section{INTRODUCTION}

Imidazole $\left(\mathrm{C}_{3} \mathrm{~N}_{2} \mathrm{H}_{4}\right)$ and its derivatives have received substantial attention owing to its relevance in not only the biological processes but also the material and drugs research and applications. As the fundamental component of histidine, purine, adenine, and guanine, imidazole (IH) plays a vital role in structure and function of many enzymes, peptides, proteins, and biomolecular complexes. ${ }^{123}$ The special structural feature enables IH acting as either proton donor or proton acceptor. This characteristic has been employed to explain not only the proton conductivity properties ${ }^{4}$ of $\mathrm{IH}$ in the solid state but also the proton transfer along a long hydrogen bonded network in the actual biological surroundings. The derivatives of $\mathrm{IH}$ have promising applications in electrode design, catalytic membrane, anion exchange membrane, and fuel cells. ${ }^{567}$ The operation of high temperature fuel cells ( $373 \mathrm{~K}$ ) provides many benefits such as strengthened tolerance of Pt catalyst on electrodes toward CO poisoning, enhanced conductivity of electrolytes, and higher available heat for utilization.

At room temperature, $\mathrm{IH}$, existing in a solid form, is an anisotropic monoclinic crystal with four molecules in a unit cell. ${ }^{8}$ The conductivity along the hydrogen bond direction of IH chain is 3 orders higher than another crystallographic direction. The rotation of all IH fragments is required to facilitate further proton transfer after the first proton delivering. ${ }^{1}$ It has been reported that the conductivity of $\mathrm{IH}$ increases by 100 times when it is heated to the melting point $(363 \mathrm{~K}){ }^{9}$ Furthermore, a new type of proton conducting material, imidazolium selenate, ${ }^{10}$ shows higher conductivity at $333 \mathrm{~K}(0.1 \mathrm{~S} / \mathrm{m})$. It is deduced that the water molecules, which generate a hydrogen bond network between imidazolium cations and selenate anions, lead to high proton conductivity, although the mechanism is still pendent. The doping of $\mathrm{IH}$ and $\mathrm{IH}$ derivatives not only increases its conductivity but also improves the chemical oxidation stability. ${ }^{11213}$

The proton conduction mechanism in IH and its derivatives via intermolecular proton transfer and $\mathrm{IH}$ reorientation have also been investigated theoretically. ${ }^{141516171819}$ Two mechanisms have been put 
forward which involve proton transfer through hydrogen bonds, either in a cooperative Grotthuss process or by migrating charged defects (Figure 1). To sustain a current, both of these mechanisms require an entire reorientation of $\mathrm{IH}$ after delivery of the first proton. The process includes the coherent rotation of all $\mathrm{IH}$ rings in the chain, with attendant lattice deformation and the concerted breaking of all hydrogen bonds. The Grotthuss mechanism is generally accepted in IH and its derivatives chains, and the rotation of IH in the chain as the rate-determining step.
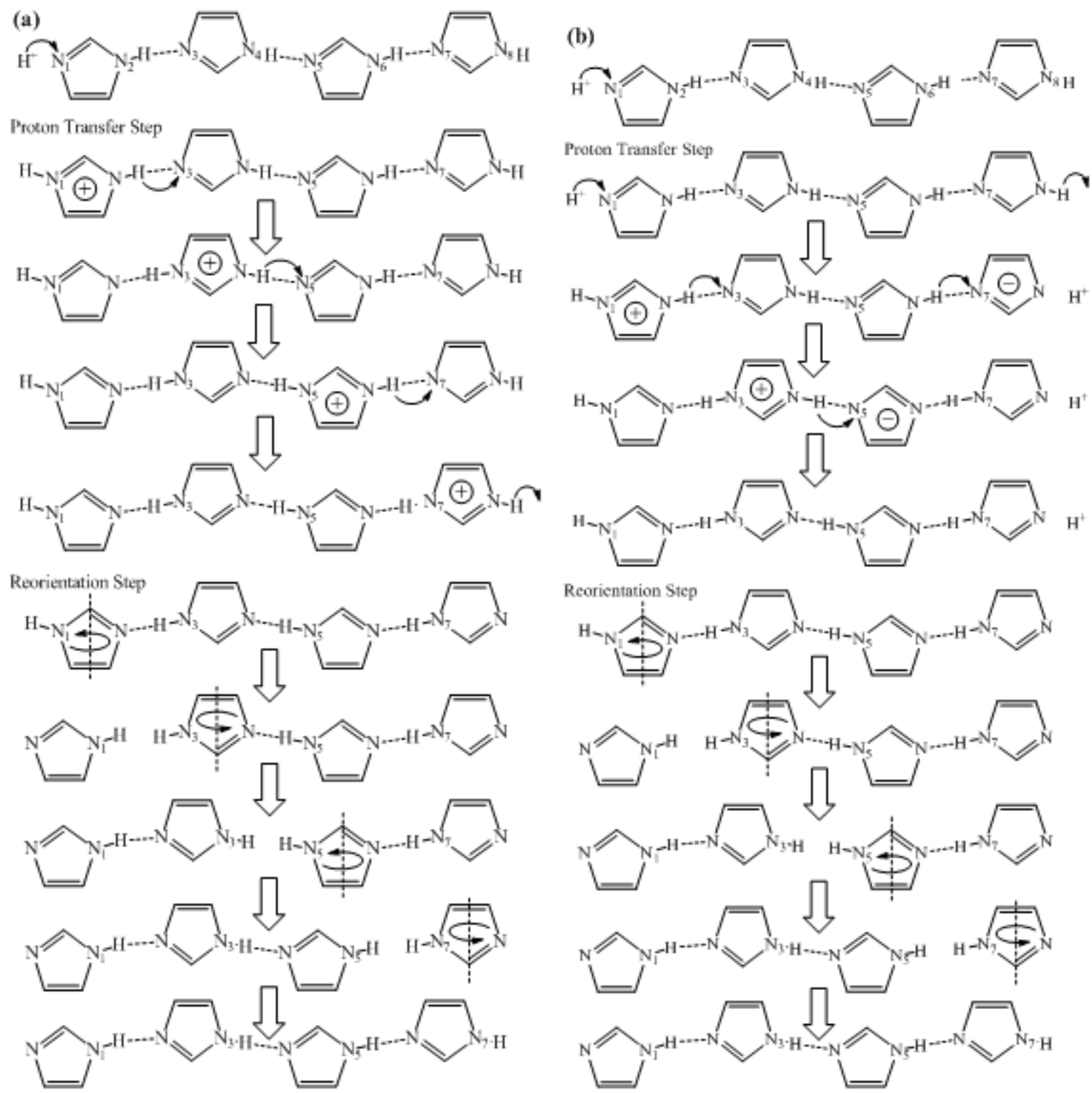

Figure1. Two proposed proton transfer mechanisms as a cooperative Grotthuss process (a) or charged defects migration (b)

$A b$ initio calculations ${ }^{20}$ indicate that $\mathrm{IH}$ acts as a proton shuttle from $\mathrm{NH}_{4}{ }^{+}$to $\mathrm{NH}_{3}$, and the proton transfer energy barrier of $\mathrm{NH}_{4}^{+} \ldots \mathrm{IH} . . . \mathrm{NH}_{3}$ is higher than that of $\mathrm{NH}_{4}{ }^{+} \ldots \mathrm{IH}$. The Car-Parrinello molecular dynamics (CPMD) simulations ${ }^{21}$ on protonated $\mathrm{IH}$ chains demonstrated that the reorientation of $\mathrm{IH}$ is a rate limiting step of proton conduction. The excess proton leads to local disorder by forming a rotational $\mathrm{IH}$ and protonated $\mathrm{IH}-\mathrm{HIH}^{+}-\mathrm{IH}$ configuration. The multistate empirical valence bond (MS-EVB) approach ${ }^{22}$ is employed in the liquid IH exploration. The results illustrate that the proton transfer energy barrier from an imidazolium cation to IH is dominated by $\mathrm{N} . . . \mathrm{N}$ distances, and the rotation of IH in the secondary solvation shell is the rate-determining step for proton transfer. The activation energy barrier of proton conduction in water and $\mathrm{IH}$ system $^{23}$ is reduced by the external electric field applied opposite to the system dipole. The characterizations on 
geometrical structure, IR spectra, relative stability, isomerization mechanism, and electronic effect of IH dimer are carried out with density functional theory method. ${ }^{2425262728}$ The electronic effects on protonated hydrogen-bonded $\mathrm{IH}$ trimer $\left(\mathrm{IH}-\mathrm{HIH}^{+}-\mathrm{IH}\right)$ and corresponding derivatives cationized by alkali metals $\left(\mathrm{Li}^{+}, \mathrm{Na}^{+}\right.$, and $\left.\mathrm{K}^{+}\right)$are explored using B3LYP method. ${ }^{29}$ Proton transfer along the hydrogen bonded water mediated $\mathrm{IH}$ chain is elucidated by employing the quantum calculations and the molecular dynamics simulations. ${ }^{30}$ It is concluded that the most favorable condition for the proton transfer in water mediated IH chain is the four-water-molecule contained IH wire with side water attached near to the acceptor IH fragment in polar solvent under higher temperature. Murli's group combines the high-pressure Raman spectroscopic with ab initio calculations on crystalline IH and suggests that the $\mathrm{CH} \ldots \mathrm{X}(\mathrm{X}=\mathrm{N}, \pi)$ and $\mathrm{NH} . . . \mathrm{N}$ intermolecular hydrogen bonds largely influence the nature of its structural and polymeric transformations under pressure. ${ }^{31}$ The proton transfer and rotational energy barriers in two- to seven- $\mathrm{IH}$-molecule chains, with and without an excess proton, are characterized $^{32}$ by density functional theory at B3LYP/6-311++G(d,p) level.

The object of this paper is to discover the proton transfer behavior between the hydrogen-bonded $\mathrm{IH}$ chains. The effect of mediated molecules, involving water and ammonia, is also considered. The emphasis is put on the effect of electronic, proton, and rotational angle to the PT mechanism. The following part collects the computational details. Then, the results and discussion are presented, including the geometrical structure, NBO charge population, IR spectra, NMR parameters, as well as the potential energy surfaces subunits. At last, the concluding remarks are collected.

\section{Computational Methods}

The hybrid density functional theory (DFT) methods are proved to be effective and inexpensive in describing large free radicals and intermolecular complexes. ${ }^{3334353637383940}$ Compared with the MP2 results, ${ }^{414243}$ although the DFT calculations using B3LYP functional predict a larger binging energy, the B3LYP functional gives results whose accuracy matches that of the best $a b$ initio results, which has been suggested in the investigations of the calculation of spin-spin coupling constants. ${ }^{444546}$ The reliability of the B3LYP/6-311++G(d,p) level has been established. ${ }^{24,26,29,47}$ Therefore, the calculations are performed employing the B3LYP density functional theory method throughout this paper at the 6$311++\mathrm{G}(\mathrm{d}, \mathrm{p})$ level as implemented in Gaussian 09 program. ${ }^{48}$

Following the geometrical structures optimization, the frequency analyses are carried out at the same level to confirm whether the optimized conformation situates at the minimum of the global potential energy surface or not and to obtain the zero-point vibrational energy (ZPVE), which is employed as a correction in calculations of the binding energy $\left(E_{\mathrm{b}}\right)$. The $E_{\mathrm{b}}$ is obtained by subtracting the energy of the complex from the sum of three components (left donor, middle chain, and right acceptor).

The continuum and atomistic solvent models have been developed. The former are computationally more tractable. In this work, the best known polarizable continuum model (PCM) ${ }^{495051}$ was employed within the framework of the self-consistent reaction field (SCRF) ${ }^{525354}$ theory, which was a continuum solvent effects of molecular properties. Solvent effects are estimated on the basis of the gas-phase geometries employing the water solvent.

The calculations of NMR parameters, chemical shift $(\delta)$ and spin-spin coupling constant $\left({ }^{\mathrm{n}} J_{\mathrm{A}, \mathrm{B}}: \mathrm{n}\right.$ is the number of covalent bond connecting A and B), are performed at B3LYP/6-311++G(d,p) level. The chemical shift value of hydrogen $\left(\delta_{\mathrm{H}}\right)$ bonded on nitrogen is obtained according to the reference tetramethylsilane molecule. The ${ }^{\mathrm{n}} J_{\mathrm{A}, \mathrm{B}}$ coupling constants are determined as a sum of the Femi-contact (FC), spin dipolar (SD), paramagnetic spin-orbit (PSO) and the diamagnetic spin-orbit (DSO) contributions.

\section{RESULTS AND DISCUSSIONS}

\subsection{Geometrical Structure}

Figure 2 presents the schematic diagrams of oxidized, neutral, reduced, protonated, and deprotonated

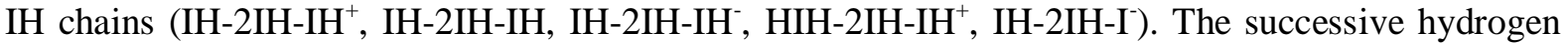
bonds connect four $\mathrm{IH}$ rings one by one with respective donor $\mathrm{NH}$ group and acceptor $\mathrm{N}$ atom. These 
four IHs in neutral system are coplanar. The NH...N hydrogen bond generation leads to the extension of $\mathrm{NH}$ bond by $\sim 0.03 \AA$ as compared to that of IH monomer. The length of this IH chain, from left $\mathrm{N}_{1}$ terminal to right $\mathrm{N}_{8}\left(\mathrm{R}\left(\mathrm{N}_{1} \ldots \mathrm{N}_{8}\right)\right)$, is $17.084 \AA$. Upon oxidation, the $\mathrm{R}\left(\mathrm{N}_{1} \ldots \mathrm{N}_{8}\right)$ distance is condensed slightly to $16.950 \AA$, accompanied with the proton transfer from the $\mathrm{N}_{2} \mathrm{H}$ group of left IHs to the neighbor acceptor $\left(\mathrm{N}_{3}\right)$. The distances of the $\mathrm{NH} . . . \mathrm{N}$ hydrogen bonds of oxidized system are all shorter as compared with those in neutral system (Figure 2). Distinct condensation of $R\left(N_{1} \ldots N_{8}\right)$ is observed upon reduction. The electron attachment leads to the proton transfer from donor $\mathrm{N}_{6} \mathrm{H}$ to right acceptor $\mathrm{N}_{7}$, the condensation of two $\mathrm{NH} . . . \mathrm{N}$ distances between left three IHs, as well as the extension of the right $\mathrm{NH} . . . \mathrm{N}$ hydrogen bond. Here, two hydrogen atoms bonded on $\mathrm{N}_{8}$ and the carbon between two nitrogen atoms depart from the plane determined by carbon and nitrogen atoms. The most significant variation upon reduction is the rotation of IHs by $\sim 90^{\circ}$ along the same direction, i.e. the neighboring IHs are perpendicular and every four IHs constitute one period. The chain length of protonated system, $\mathrm{HIH}-2 \mathrm{IH}-\mathrm{IH}^{+}$, is condensed by $\sim 0.32 \AA$ as compared with the $\mathrm{R}\left(\mathrm{N}_{1} \ldots \mathrm{N}_{8}\right)$ of oxidized $\mathrm{IH}-2 \mathrm{IH}-\mathrm{IH}^{+}$. As compared with the neutral system, the protonation leads to both the condensation of the chain (from 17.084 to $16.626 \AA$ ) and the rotation of left IHs by $90^{\circ}$, the left bare $\mathrm{N}$ atom of which combines with the additional proton. When the proton is detached from the right $\mathrm{N}_{8} \mathrm{H}$ group, every two IHs rotate by $\sim 90^{\circ}$ and the $\mathrm{R}\left(\mathrm{N}_{1} \ldots \mathrm{N}_{8}\right)$ length is obviously condensed to 15.479 $\AA$.

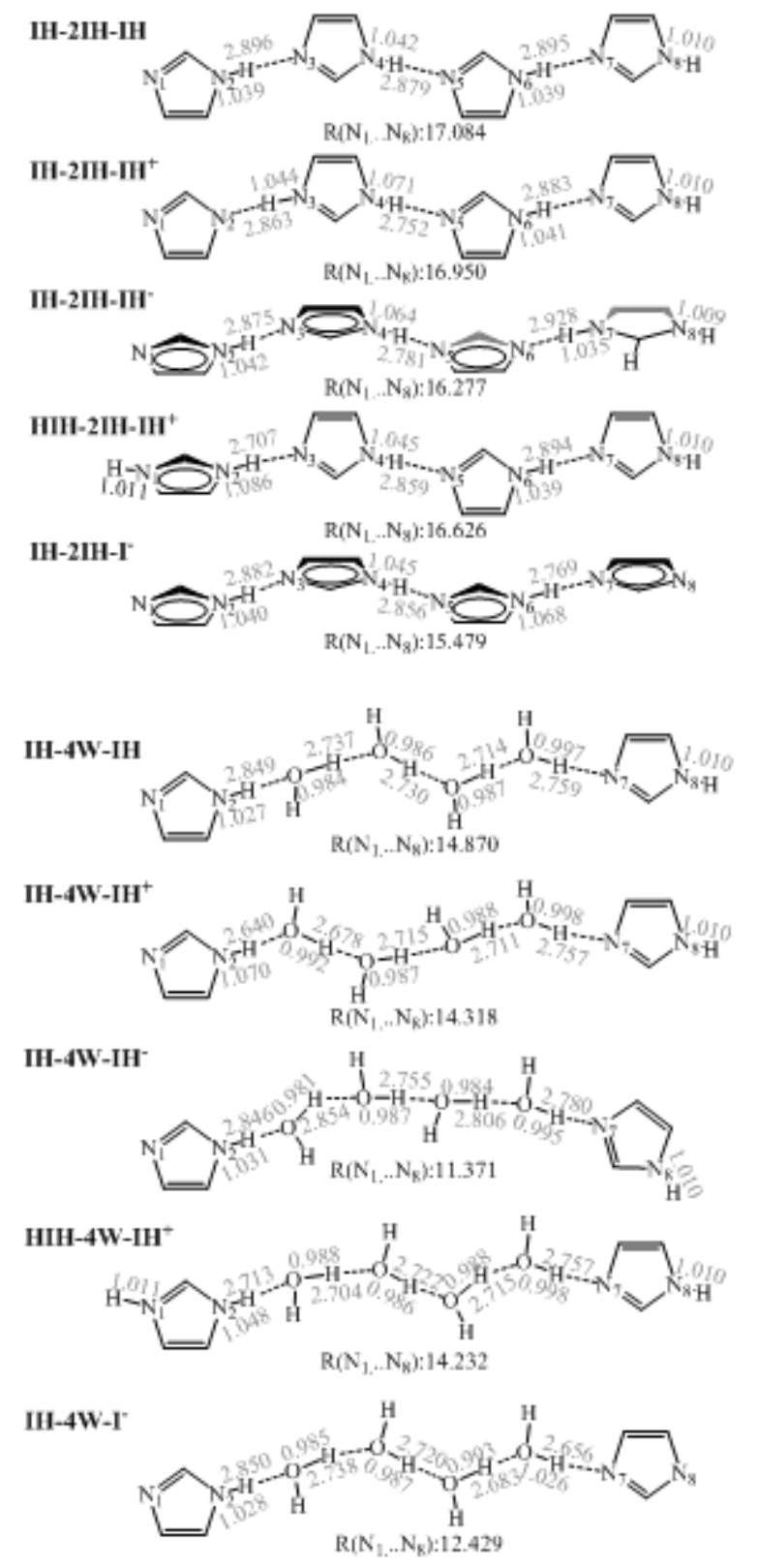




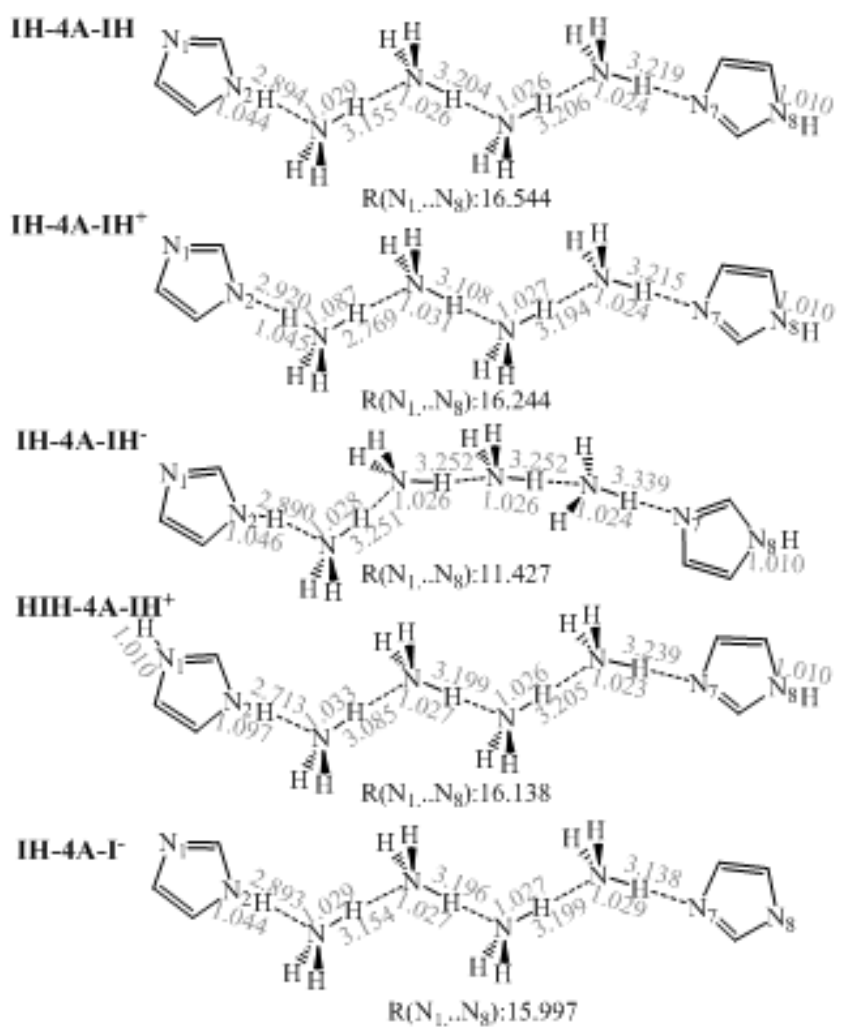

Figure2. Sketch maps for neutral, oxidized, reduced, protonated, as well as the deprotonated imidazole, water, and ammonia mediated chains

In water mediated chains, two middle IHs are substituted by four water molecules. Five hydrogen bonds connect the terminal IHs and four mediated water molecules together. The chain length $\mathrm{R}\left(\mathrm{N}_{1} \ldots \mathrm{N}_{8}\right)$ of the neutral system, IH-4W-IH, is $14.870 \AA$. As compared with the NH...N hydrogen bond in $\mathrm{IH}-2 \mathrm{IH}-\mathrm{IH}$, the distances of $\mathrm{NH} \ldots \mathrm{O}, \mathrm{OH} . . \mathrm{N}$, and $\mathrm{OH} . . \mathrm{O}$ hydrogen bonds in $\mathrm{IH}-4 \mathrm{~W}-\mathrm{IH}$ are shorter in varying degrees. The oxidation upon electron detachment leads to the reduction of $\mathrm{R}\left(\mathrm{N}_{1} \ldots \mathrm{N}_{8}\right)$ by $\sim 0.55 \AA$ for the water mediated system. The distance of $\mathrm{N}_{2} \mathrm{H}$ extends by $0.043 \AA$ upon oxidation, dislike that in IHs mediated system. The chain condensed by $\sim 3.50 \AA$ upon reduction owing to the electron attachment because of the rearrangement of four water molecules and the rotation of terminal $\mathrm{IHs}$ acceptor. In the reduced $\mathrm{IH}-4 \mathrm{~W}-\mathrm{IH}^{-}$, two terminal $\mathrm{IHs}$ perpendicular to each other, similar to the situation in IH mediated cluster. The chain length of protonated cluster, HIH-4W$\mathrm{IH}^{+}$, is almost equal to that of the oxidized system. The conjunction of additional proton with $\mathrm{N}_{1}$ enhances the attraction between left donor IH fragment with the following water molecules, as is reflected by distances of following $\mathrm{NH} . . . \mathrm{O}$ and $\mathrm{OH} . . . \mathrm{O}$ hydrogen bonds. The proton is detached from the right acceptor $\mathrm{IH}$ fragment in the deprotonated cluster, IH-4W-I. The interaction between the deprotonated $\mathrm{IH}$ and the former water molecules is enlarged as compared with the coupling between neutral $\mathrm{IH}$ and water. As is reflected by the corresponding hydrogen bonds distances.

The chain length of neutral ammonia mediated system (IH-4A-IH) is $16.544 \AA$, shorter by $0.540 \AA$ than that of IH-2IH-IH. The hydrogen bonds, with the ammonia as donor group, are longer distinctly than those observed in IH and water mediated chains. Upon oxidation, the chain length is reduced by $0.300 \AA$ and the proton transfers from $\mathrm{N}_{2}$ to the approaching ammonia molecule. As is similar to that of IH mediated system. Electron attaching attracts the terminal IHs and the mediated ammonia close together, and the $\mathrm{R}\left(\mathrm{N}_{1} \ldots \mathrm{N}_{8}\right)$ distance reduces to $11.427 \AA$, almost equal to that of IH- $4 \mathrm{~W}-\mathrm{IH}^{-}$. The bend of the chain leads to the approaching of side ammonia molecules with a short $\left(\mathrm{N}_{3}\right) \mathrm{H} \ldots \mathrm{H}\left(\mathrm{N}_{6}\right)$ distance (3.374 $\AA$ ). Protonation leads to the extension of $\mathrm{N}_{2} \mathrm{H}(0.053 \AA)$ as well as the condensation of $\mathrm{R}\left(\mathrm{N}_{1} \ldots \mathrm{N}_{8}\right) \quad(0.406 \AA)$ and left three $\mathrm{NH} \ldots \mathrm{N}$ hydrogen bonds. In deprotonated IH-4A-I', proton detachment enhances the electron density on right $\mathrm{IH}$ acceptor, then strengthens the interaction between it and the approaching three ammonia molecules. 


\subsection{Charge Population}

The natural bond orbital (NBO) charge population on four IHs of neutral IH-2IH-IH is near to zero. The proton transfer from $\mathrm{N}_{2}$ to $\mathrm{N}_{3}$ upon oxidation leads to most of the positive NBO charges $(0.842 \mathrm{e})$ populated on the left second IH. Electron attachment leads to proton transfer from the right second IH to the terminal acceptor, accompanied by the negative NBO charges populated predominantly on the right second IH (-0.853 e). Different with the oxidized system, the positive NBO charges of the protonated $\mathrm{HIH}-2 \mathrm{IH}-\mathrm{IH}^{+}$locates mainly on left terminal $\mathrm{IH}(0.884 \mathrm{e})$, instead of the left second $\mathrm{IH}$. No proton transfer occurs upon proton detachment, therefore, most of the negative NBO charges ($0.902 \mathrm{e}$ ) of $\mathrm{IH}^{-2} \mathrm{IH}^{-} \mathrm{I}^{-}$populates on right terminal $\mathrm{IH}$ fragment. Therefore, it is helpful to discover the proton conduction mechanism with the detection of NBO charges.

The NBO charges populated on each fragments of neutral IH-4W-IH system is near to zero. No proton transfer occurs upon either oxidation or protonation, which leads to the concentration of positive NBO charges on left donor IH fragment $(0.912$ and $0.937 \mathrm{e})$. The reduction upon electron attachment leads to the condensation of water chain, and the NBO charges populates mainly on the first and the third water molecules from the left donor IH. The NBO charges in proton detached IH-4W-I' system locates mainly on right acceptor IH fragment.

No significant NBO charges is observed in every fragment of neutral IH-4A-IH cluster. Similar to IH mediated system, the proton transfers from left donor IH upon oxidation. The positive NBO charges of $\mathrm{IH}-4 \mathrm{~A}-\mathrm{IH}^{+}$populates mainly $(0.837 \mathrm{e})$ on the neighboring ammonia of the left terminal $\mathrm{IH}$. The protonation of left terminal IH leads to the extension of $\mathrm{N}_{2} \mathrm{H}$, and some of the positive NBO charges is observed on its neighboring fragment $(0.110 \mathrm{e})$, although most of the charges still remains on left IH $(0.857 \mathrm{e})$. The approaching of two side ammonia molecules in the reduced $\mathrm{IH}-4 \mathrm{~A}-\mathrm{IH}^{-}$system traps the NBO charges with the short H...H interaction. Almost all of the negative charges $(-0.975 \mathrm{e})$ remains in the right acceptor $\mathrm{IH}$ fragment in IH-4A-I' owing to the proton detachment.

The molecular electrostatic potentials (ESP) of these chains are collected in Figure 3. Some useful information about the charge population can also be abstracted from these diagrams. Red-color and blue-color surfaces denote the negative electrostatic zone and the positive electrostatic area, respectively. In neutral systems $(\mathrm{IH}-2 \mathrm{IH}-\mathrm{IH}, \mathrm{IH}-4 \mathrm{~W}-\mathrm{IH}$, and $\mathrm{IH}-4 \mathrm{~A}-\mathrm{IH})$, the left terminal bared $\mathrm{N}_{1}$ and the right terminal $\mathrm{N}_{8} \mathrm{H}$ group locate in negative and positive areas, respectively. Distinct positive surface is observed around the second fragment of $\mathrm{IH}-2 \mathrm{IH}-\mathrm{IH}^{+}$and $\mathrm{IH}-4 \mathrm{~A}-\mathrm{IH}^{+}$owing to the proton transfer. For the water mediated $\mathrm{IH}-4 \mathrm{~W}-\mathrm{IH}^{+}$chain, the positive surface is surrounding the left terminal $\mathrm{IH}$ fragment. As is similar to the case of protonated systems. The negative surface surrounds the IH molecule, where the proton is transferred to the right acceptor of $\mathrm{IH}-2 \mathrm{IH}-\mathrm{IH}^{-}$. The negative surfaces of $\mathrm{IH}-4 \mathrm{~W}-\mathrm{IH}^{-}$and $\mathrm{IH}-4 \mathrm{~A}-\mathrm{IH}^{-}$surround predominantly the space composed by the mediated molecules

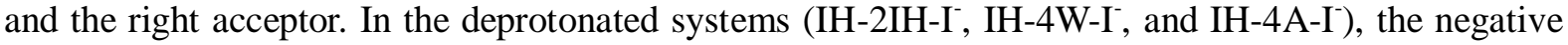
surface populates mainly on the right terminal IH ring.

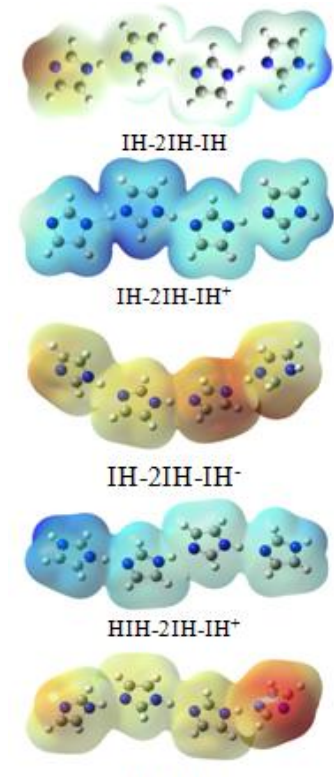

IH-2IH-I-

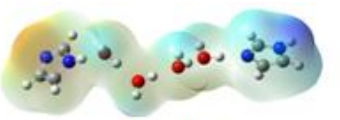

IH-4W-IH

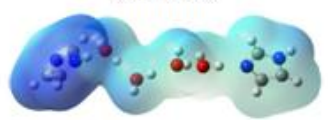

IH-4W- IH $^{+}$

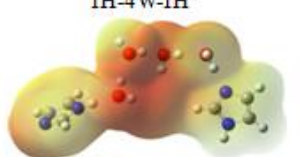

IH-4W-IH

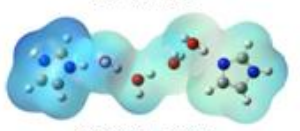

HIH-4W-IH ${ }^{+}$

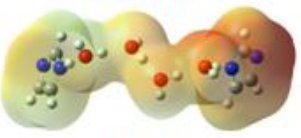

IH-4W-I

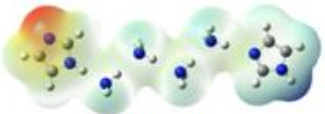

IH-4A-IH

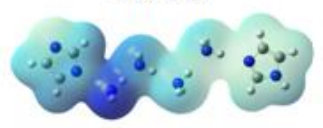

$\mathrm{IH}-4 \mathrm{~A}-\mathrm{IH}^{+}$

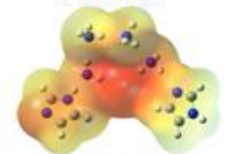

IH-4A- $\mathrm{IH}^{-}$

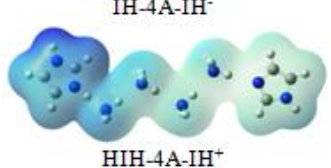

HIH-4A-IH+

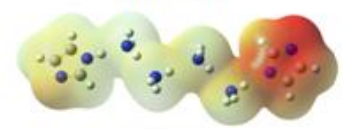

IH-4A-I-

Figure3. Electrostatic potential of the imidazole, water, and ammonia mediated complexes. The blue surface represents the positive surface of the electrostatic potential, and the red area denotes the negative zone 
The variation upon oxidation and reduction occurs mainly on the frontier molecular orbitals: the highest occupied molecular orbital (HOMO) and the lowest unoccupied molecular orbital (LUMO). The frontier molecular orbitals of three neutral chains (IH-2IH-IH, IH-4W-IH, and IH-4A-IH) and the spin densities of the corresponding charged systems are collected in Figure 4. The spin densities of the oxidized system locates on respective left donor IH fragment, which is the HOMO orbital of corresponding neutral system. The spin densities of the reduced system populate on the site where LUMO orbital occupies. As indicates that the electron is detached from the HOMO orbital upon oxidation and is attached on the LUMO orbital upon reduction. The spin densities of $\mathrm{IH}-4 \mathrm{~W}-\mathrm{IH}^{-}$and $\mathrm{IH}-4 \mathrm{~A}-\mathrm{IH}^{-}$illustrates the existence of solvent electron, which attracts the electropositive atoms strongly and condenses the chain length.

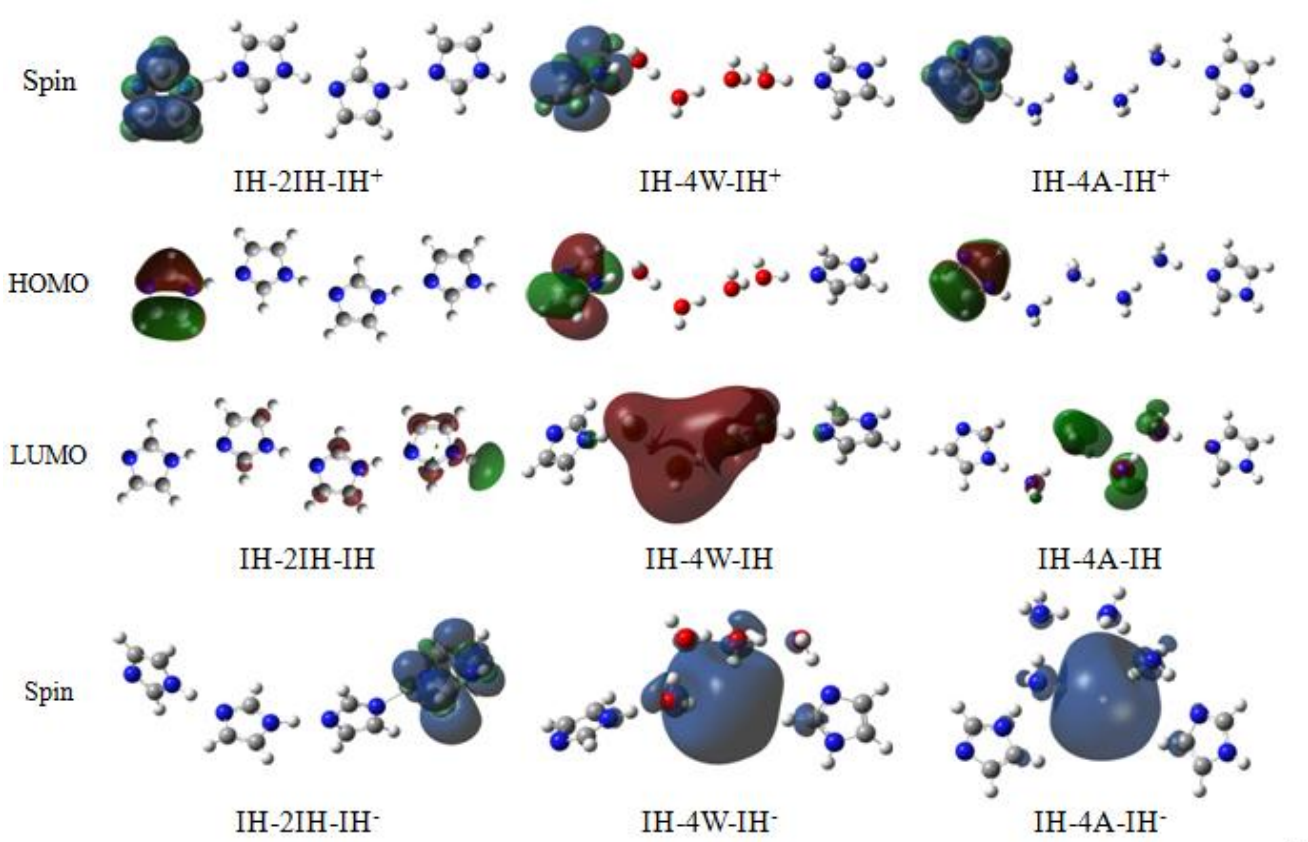

Figure4. The frontier molecular orbitals of the neutral imidazole, water, and ammonia mediated complexes, as well as the spin density of the oxidized and reduced systems

\subsection{IR Spectra}

As a helpful tool in chemistry, medical, material, and biological structural determination, IR spectroscopy has been employed extensively. It is sensitive to the type of bonded atom, the bond order, and the chemical environment. The IR vibrational frequency analyses are performed to get related structural information as well as to validate the structure corresponding to the local minima on the global potential energy surface. Figure 5 shows the IR spectra of imidazole, water, and ammonia mediated chains.

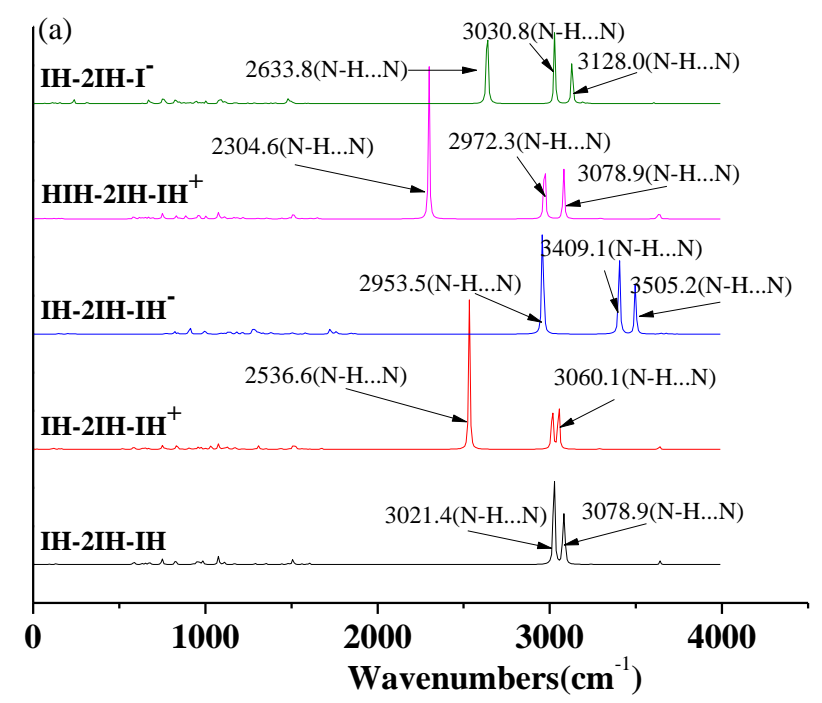



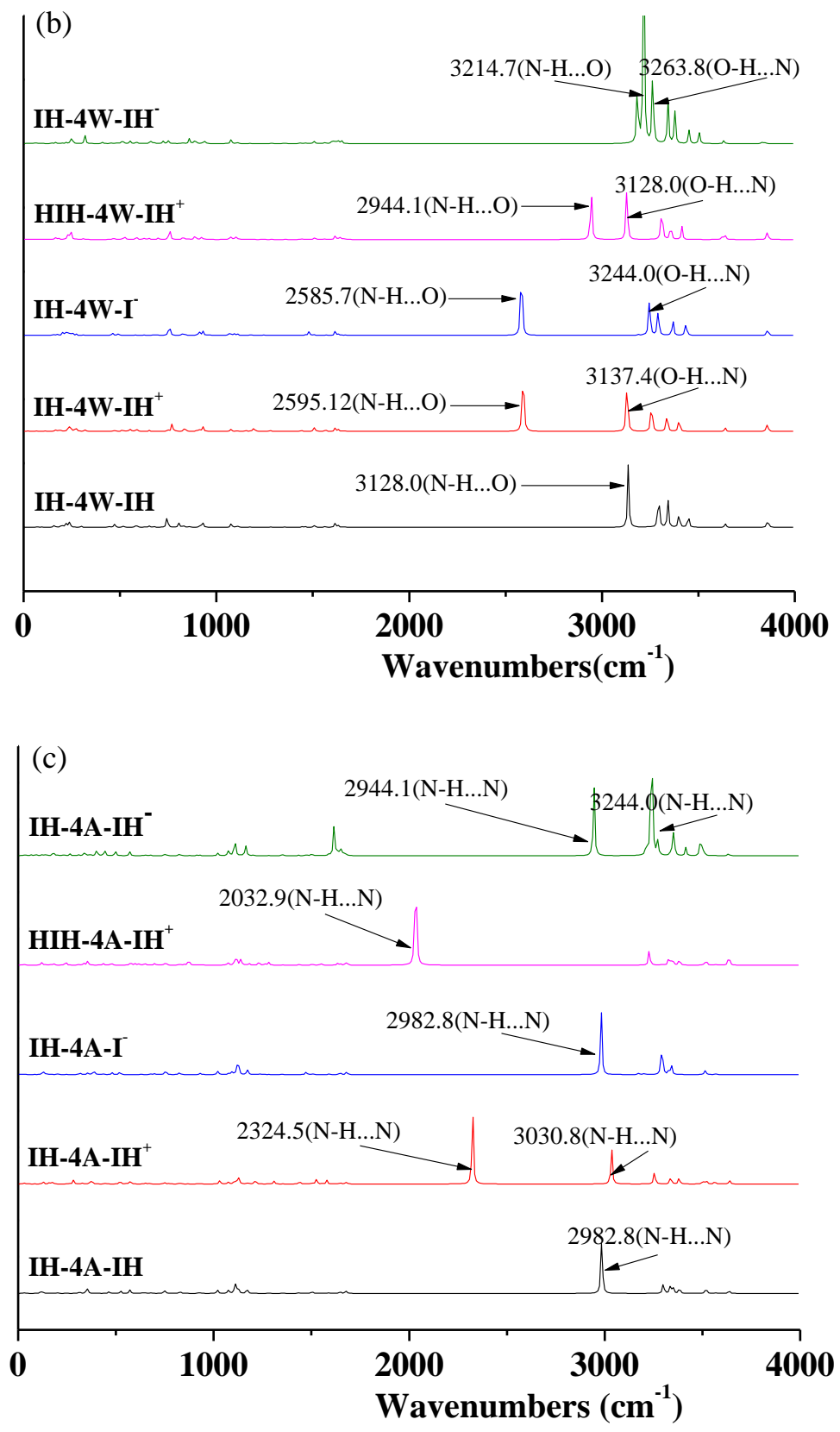

Figure5. IR Spectra of imidazole, water, and ammonia mediated chains calculated at B3LYP/6-311++G* level

The characteristic vibrations of $\mathrm{N}_{2} \mathrm{H} \ldots \mathrm{N}_{3}, \mathrm{~N}_{4} \mathrm{H} \ldots \mathrm{N}_{5}$, and $\mathrm{N}_{6} \mathrm{H} \ldots \mathrm{N}_{7}$ hydrogen bonds in neutral IH-2IHIH system are assigned at 3074.9, 3024.6, and $3084.6 \mathrm{~cm}^{-1}$, respectively (Table 1). The vibrational numbers of $\mathrm{N}_{2} \mathrm{H} \ldots \mathrm{N}_{3}$ and $\mathrm{N}_{6} \mathrm{H} \ldots \mathrm{N}_{7}$ stretching approach to each other, looking like a single signal. The middle $\mathrm{NH}$...N stretching is red-shifted to $2532.8 \mathrm{~cm}^{-1}$ upon oxidation owing to the proton transfer from left IH. The other two hydrogen bonds in the oxidized IH chain are red-shifted slightly. Significant red-shift $\left(438.1 \mathrm{~cm}^{-1}\right)$ is observed for the middle $\mathrm{NH}$...N hydrogen bond in the reduced system. Along with the proton transfer to right terminal IH, blue-shift by $45.4 \mathrm{~cm}^{-1}$ is observed for the right $\mathrm{NH}$... N hydrogen bond stretching. The proton addition on left IH leads to significant red-shift of left $\mathrm{N}_{2} \mathrm{H} \ldots \mathrm{N}_{3}$ stretching by $776.5 \mathrm{~cm}^{-1}$. The effect on the other two $\mathrm{NH} . . . \mathrm{N}$ hydrogen bonds decreases gradually, as is reflected by the wavenumbers of their stretching. On the contrary, the proton detachment from right $\mathrm{IH}$ bring significant effect to $\mathrm{N}_{6} \mathrm{H} \ldots \mathrm{N}_{7}$ (red-shift by $510.1 \mathrm{~cm}^{-1}$ ). The effect decreases gradually from right to left. 
Table1. Primary vibrational frequency $\left(\mathrm{cm}^{-1}\right)$ of imidazole, water, and ammonia mediated systems

\begin{tabular}{|c|c|c|c|c|c|}
\hline Complex & IH-2IH-IH & IH-2IH-IH & IH-2IH-IH $^{+}$ & HIH-2IH-IH $^{+}$ & IH-2IH-I $^{-1}$ \\
\hline $\mathrm{N}_{2} \mathrm{H} \ldots \mathrm{N}_{3}$ & 3074.9 & 3015.0 & 3028.7 & 2298.4 & 3053.2 \\
\hline $\mathrm{N}_{4} \mathrm{H} \ldots \mathrm{N}_{5}$ & 3024.6 & 2532.8 & 2636.8 & 2969.8 & 2969.7 \\
\hline $\mathrm{N}_{6} \mathrm{H} \ldots \mathrm{N}_{7}$ & 3084.6 & 3051.5 & 3130.0 & 3080.5 & 2574.5 \\
\hline $\mathrm{Complex}$ & $\mathbf{I H - 4 W - I H}$ & $\mathbf{I H - 4 W}-\mathbf{I H}^{+}$ & IH-4W-IH $^{-}$ & HIH-4W-IH $^{+}$ & IH-4W-I $^{-}$ \\
\hline $\mathrm{N}_{2} \mathrm{H} \ldots \mathrm{O}_{3}$ & 3294.0 & 2591.3 & 3216.4 & 2944.2 & 3291.8 \\
\hline $\mathrm{O}_{6} \mathrm{H} \ldots \mathrm{N}_{7}$ & 3136.7 & 3130.4 & 3183.2 & 3129.3 & 2582.3 \\
\hline $\mathrm{Complex}$ & $\mathbf{I H - 4 A - I H}$ & IH-4A-IH $^{+}$ & IH-4A-IH $^{-}$ & HIH-4A-IH $^{+}$ & IH-4A-I $^{-}$ \\
\hline $\mathrm{N}_{2} \mathrm{H} \ldots \mathrm{N}_{3}$ & 2985.1 & 3035.1 & 2945.3 & 2033.6 & 2982.3 \\
\hline $\mathrm{N}_{6} \mathrm{H} \ldots \mathrm{N}_{7}$ & 3383.2 & 3381.4 & 3414.8 & 3382.7 & 3289.2 \\
\hline
\end{tabular}

In water mediated system, the $\mathrm{N}_{2} \mathrm{H} . . . \mathrm{O}_{3}$ and $\mathrm{O}_{6} \mathrm{H} . . . \mathrm{N}_{7}$ stretching modes are assigned at 3294.0 and $3136.7 \mathrm{~cm}^{-1}$, respectively (Table 1 ). The $\mathrm{N}_{2} \mathrm{H} \ldots \mathrm{O}_{3}$ stretching vibrational frequency red shifts by 702.7 $\mathrm{cm}^{-1}$ upon oxidation, and the variation of $\mathrm{O}_{6} \mathrm{H} . . . \mathrm{N}_{7}$ is slight. Similar phenomenon is observed upon protonation. As might contribute to the geometrical changes upon oxidation and protonation. Significant red-shift $\left(554.4 \mathrm{~cm}^{-1}\right)$ of $\mathrm{O}_{6} \mathrm{H} \ldots \mathrm{N}_{7}$ stretching is observed in the deprotonated $\mathrm{IH}_{-}-4 \mathrm{~W}-\mathrm{I}^{-}$ system. The electron attachment varies mainly the water chain structure, and the effect on both terminal hydrogen bonds ( $\mathrm{NH} \ldots \mathrm{O}$ and $\mathrm{OH} \ldots \mathrm{N})$ is slight.

The $\mathrm{N}_{2} \mathrm{H} . . . \mathrm{N}_{3}$ and $\mathrm{N}_{6} \mathrm{H} . . . \mathrm{N}_{7}$ stretching vibrations in ammonia mediated neutral system are assigned at 2985.1 and $3383.2 \mathrm{~cm}^{-1}$, respectively. Blue-shift by $50.0 \mathrm{~cm}^{-1}$ upon oxidation and red-shift by $39.8 \mathrm{~cm}^{-}$ ${ }^{1}$ upon reduction are observed for the $\mathrm{N}_{2} \mathrm{H}$... $\mathrm{N}_{3}$ stretching. Blue-shift by $31.6 \mathrm{~cm}^{-1}$ upon reduction is observed for the stretching of $\mathrm{N}_{6} \mathrm{H} . . . \mathrm{N}_{7}$ hydrogen bond. The $\mathrm{N}_{2} \mathrm{H}$.... $\mathrm{N}_{3}$ stretching is red-shifted significantly by $951.5 \mathrm{~cm}^{-1}$ upon protonation, indicating the weaken of this hydrogen bond. The protonation effect on right $\mathrm{N}_{6} \mathrm{H}$... $\mathrm{N}_{7}$ hydrogen bond is slight, as is reflected by its vibrational frequency. The deprotonation effect mainly on the right $\mathrm{N}_{6} \mathrm{H} . . . \mathrm{N}_{7}$ hydrogen bond.

\subsection{NMR Parameters}

\subsubsection{Chemical Shift $(\delta)$}

The chemical shifts of the hydrogen atoms $\left(\delta_{\mathrm{H}}\right)$ in the hydrogen bonded network are collected in Table 2. In the IH mediated neutral chain, the $\delta_{\mathrm{H}}$ differentiation of left three hydrogen atoms is slight and larger than that of the left hydrogen atom $\left(\delta_{\mathrm{H} 8}\right)$. Upon oxidation, significant variation is observed for $\delta_{\mathrm{H} 4}$ owing to the proton transfer from the left $\mathrm{IH}$ to $\mathrm{N}_{3}$. While, the $\delta_{\mathrm{H}}$ value of left three hydrogen atoms changes distinctly upon reduction because the IHs rotation and the proton transfer from $\mathrm{N}_{6}$ to right $\mathrm{IH}$ fragment. Protonation enhances the $\delta_{\mathrm{H} 2}$ predominantly and the effect on other hydrogen atoms decreases along the distance with the excess proton. On the contrary, the effect on $\delta_{\mathrm{H}}$ in deprotonated $\mathrm{IH}-2 \mathrm{IH}^{-} \mathrm{I}^{-}$chain decreases along the distance with the right $\mathrm{IH}$ fragment.

For the water mediated IH-4W-IH chain, the oxidation effect on $\delta_{\mathrm{H}}$ decreases gradually from $\mathrm{H} 2$ (4.60 $\mathrm{ppm})$ to $\mathrm{H} 8(0.00 \mathrm{ppm})$. The effect of reduction on $\delta_{\mathrm{H}}$ can be observed obviously for the hydrogen atoms in the hydrogen bond network owing to the excess electron location. The influence of protonation is similar to that of oxidation, viz. decreases progressively along the distance with the additional proton. The variation of $\delta_{\mathrm{H}}$ increases along with the approaching to right $\mathrm{IH}$ fragment in deprotonated IH-4W-I' system.

The substitution of $\mathrm{IH}$ by ammonia brings slight influence on $\delta_{\mathrm{H}}$ of donor and acceptor fragments (Table 2). The oxidation leads to the proton transfer from left donor fragment to the approaching ammonia. As increases the value of $\delta_{\mathrm{H} 3}$ by $10.05 \mathrm{ppm}$. The influence to $\delta_{\mathrm{H}}$ decreases gradually from left (H4) to right (H8). Similar to the water mediated chain, the rearrangement of the middle ammonia molecules upon reduction brought significant influence on the corresponding hydrogen atoms. The variation of $\delta_{\mathrm{H}}$ upon protonation also decreases obviously from $\mathrm{H} 2(5.02 \mathrm{ppm})$ to $\mathrm{H} 8(0.01 \mathrm{ppm})$. The deprotonation effect on $\delta_{\mathrm{H}}$ increases clearly from left $(0.02 \mathrm{ppm})$ to right $(1.39 \mathrm{ppm})$. 
Table2. ${ }^{1} H$ Chemical shift (ppm) for the imidazole, water, and ammonia mediated chains obtained with the reference of TMS at B $3 L Y P / 6-311++G^{*}$ level

\begin{tabular}{|c|c|c|c|c|c|c|}
\hline Complex & $\delta_{\mathrm{H} 2}$ & $\delta_{\mathrm{H} 3}$ & $\delta_{\mathrm{H} 4}$ & $\delta_{\mathrm{H} 5}$ & $\delta_{\mathrm{H} 6}$ & $\delta_{\mathrm{H} 8}$ \\
\hline IH-2IH-IH & 15.49 & & 15.84 & & 15.44 & 9.21 \\
\hline IH-2IH-IH $^{+}$ & 15.73 & & 18.94 & & 15.67 & 9.21 \\
\hline IH-2IH-IH & 15.87 & & 18.48 & & 11.71 & 4.60 \\
\hline HIH-2IH-IH $^{+}$ & 20.22 & & 16.25 & & 15.45 & 9.21 \\
\hline IH-2IH-I' & 15.70 & & 16.32 & & 18.86 & \\
\hline IH-4W-IH & 13.25 & 7.21 & 7.24 & 7.67 & 9.65 & 9.12 \\
\hline IH-4W-IH ${ }^{+}$ & 17.85 & 8.81 & 7.64 & 7.76 & 9.70 & 9.12 \\
\hline IH-4W-IH & 13.58 & 4.65 & 5.54 & 6.22 & 8.85 & 8.97 \\
\hline HIH-4W-IH ${ }^{+}$ & 15.90 & 8.15 & 7.47 & 7.71 & 9.73 & 9.12 \\
\hline IH-4W-I' & 13.20 & 7.23 & 7.45 & 8.40 & 13.27 & \\
\hline IH-4A-IH & 15.64 & 5.14 & 4.23 & 4.12 & 3.88 & 9.08 \\
\hline $\mathrm{IH}^{-4 A-\mathrm{IH}^{+}}$ & 9.91 & 15.19 & 5.83 & 4.32 & 3.92 & 9.09 \\
\hline IH-4A-IH $^{-}$ & 15.72 & 3.56 & 3.18 & 2.89 & 2.61 & 9.08 \\
\hline HIH-4A-IH $^{+}$ & 20.66 & 6.46 & 4.41 & 4.13 & 3.90 & 9.09 \\
\hline IH-4A-I' & 15.66 & 5.18 & 4.33 & 4.30 & 5.27 & \\
\hline
\end{tabular}

\subsubsection{Spin-Spin Coupling Constant (J)}

Table 3 collects the NMR $J$ of N-H $\left({ }^{1} J_{\mathrm{N}, \mathrm{H}}\right)$ for the optimized IH, water, and ammonia mediated chains. The ${ }^{1} J_{\mathrm{N}, \mathrm{H}}$ in the water mediated chains varies around $65 \mathrm{~Hz}$, in good agreement with those observed previously. ${ }^{30}$ The following two points can be abstracted from Table 3. Firstly, the proton transfer can be characterized by the ${ }^{1} J_{\mathrm{N}, \mathrm{H}}$ value, viz. the large positive value corresponds to the non-proton transferred case and the small negative data refers to the proton transferred situation. Secondly, the ${ }^{1} J_{\mathrm{N}, \mathrm{H}}$ value is related tightly with the bonding characteristics of $\mathrm{N}$, reflected by the difference of ${ }^{1} J_{\mathrm{N}, \mathrm{H}}$ between the IH N-H and the ammonia N-H. Figure 6 presents the relationship between the NMR $J$ $\left({ }^{2} J_{\mathrm{N}, \mathrm{N}}\right)$ and the distance of NH...N hydrogen bond. The black square point and the red ball point denote the ${ }^{2} J_{\mathrm{N}, \mathrm{N}}$ in IH and ammonia mediated chains, respectively. It is obvious that the ${ }^{2} J_{\mathrm{N}, \mathrm{N}}$ value decreases linearly with the $\mathrm{N}$...N distance.

Table3. Selected spin-spin coupling constants (SSCC: Hz) for the imidazole, water, and ammonia mediated chains

\begin{tabular}{|c|c|c|c|c|c|}
\hline SSCC & IH-2IH-IH & IH-2IH-IH $^{+}$ & IH-2IH-IH $^{-}$ & HIH-2IH-IH $^{+}$ & IH-2IH-I' \\
\hline${ }^{1} J_{\mathrm{N} 2, \mathrm{H}}$ & 63.8 & -1.9 & 63.4 & 58.0 & 63.5 \\
\hline${ }^{1} J_{\mathrm{N} 4, \mathrm{H}}$ & 63.7 & 60.7 & 60.0 & 63.6 & 63.2 \\
\hline${ }^{1} J_{\mathrm{N} 6, \mathrm{H}}$ & 64.2 & 64.2 & -2.4 & 64.3 & 59.4 \\
\hline${ }^{1} J_{\mathrm{N} 8, \mathrm{H}}$ & 66.6 & 66.7 & 61.1 & 66.6 & \\
\hline & IH-4W-IH & $\mathrm{IH}^{-4 \mathrm{~W}-\mathrm{IH}^{+}}$ & IH-4W-IH & HIH-4W-IH $^{+}$ & IH-4W-I' \\
\hline${ }^{1} J_{\mathrm{N} 2, \mathrm{H}}$ & 65.4 & 62.9 & 65.0 & 65.4 & 65.3 \\
\hline${ }^{1} J_{\mathrm{N} 4, \mathrm{H}}$ & 66.8 & 66.8 & 66.7 & 66.8 & \\
\hline & IH-4A-IH & IH-4A-IH ${ }^{+}$ & IH-4A-IH $^{-}$ & HIH-4A-IH $^{+}$ & IH-4A-I \\
\hline${ }^{1} J_{\mathrm{N} 2, \mathrm{H}}$ & 62.7 & -2.4 & 62.4 & 54.1 & 62.7 \\
\hline${ }^{1} J_{\mathrm{N} 3, \mathrm{H}}$ & 43.4 & 41.9 & 42.1 & 44.3 & 43.3 \\
\hline${ }^{1} J_{\mathrm{N} 4, \mathrm{H}}$ & 42.9 & 43.9 & 42.8 & 42.9 & 42.9 \\
\hline${ }^{1} J_{\mathrm{N} 5, \mathrm{H}}$ & 42.9 & 43.0 & 42.8 & 42.9 & 42.8 \\
\hline${ }^{1} J_{\mathrm{N} 6, \mathrm{H}}$ & 42.7 & 42.7 & 40.6 & 42.7 & 43.1 \\
\hline${ }^{1} J_{\mathrm{N} 8, \mathrm{H}}$ & 66.3 & 66.3 & 66.1 & 66.3 & \\
\hline
\end{tabular}




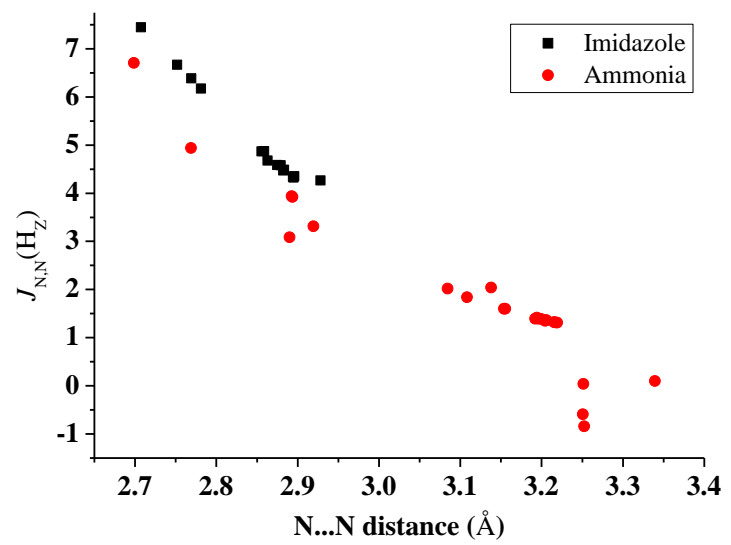

Figure6. The NMR spin-spin coupling constants of approaching N...N pair in imidazole and ammonia mediated systems

\subsection{Potential Energy Surfaces}

Multi-proton transfer in hydrogen bonded systems is one of the most fundamental processes in chemistry and biology, and has attracted extensive attention. ${ }^{5565758}$ It has been pointed out that the rotation of $\mathrm{IH}$ fragments is inevitable during the proton transfer process. ${ }^{7}, 13,21,32,59$ The twodimensional proton transfer potential energy surfaces (PESs) of water mediated $\mathrm{IH}$ system has been performed, with a barrier of a few $\mathrm{kcal} / \mathrm{mol},{ }^{30}$ while the effect of electronic and protonic state, as well as the rotational sequence of each $\mathrm{IH}$ fragment on the proton transfer are not revealed. Here, the rotational barriers of every IH fragments in various states are explored and expressed in Figure 7.

Plot (a) indicates that two terminal IH fragments rotate freely in neutral state system. While the fragment rotation of two middle IH rings needs to overcome the barrier of $\sim 8 \mathrm{kcal} / \mathrm{mol}$. For the cationic chains (Plot (b)), the rotation of two terminal IH fragments is barrierless. The barrier of the third fragment rotation is over $10 \mathrm{kcal} / \mathrm{mol}$. It is impossible for the rotation of the second $\mathrm{IH}$ ring due to its high barrier of $\sim 70 \mathrm{kcal} / \mathrm{mol}$. The situation is similar for the fragments rotation of anionic system, which is shown in plot (c). While for the deprotonated system (Plot (e)), the rotation of the third fragment is hard with the barrier $\sim 75 \mathrm{kcal} / \mathrm{mol}$. The relative energy of the protonated IH mediated system along the rotation of each fragment are drawn in Plot (d). It is clear that the rotation of the posterior three fragments is easier to accomplish as compared with that of the first one, which carriers the excess proton. Combined the geometrical structure characteristics of these chains, it can be drawn that the rotation of IH fragment can be conveniently fulfilled except that bearing an excess proton or that hydrogen bonded with the deprotonated IH fragment.

Thus, two conduction mechanisms in IH mediated system are expected as following. Firstly, electron transfer from/to the IH chain upon oxidation/reduction. Then, the terminal fragments rotate and the geometrical structure is rearranged. The rotation of mediated IH rings occurs and then the system recovers. Secondly, protonation/deprotonation occurs initially, followed by the fragment rotation and the geometrical rearrangement. Then, the protonated fragment for the protonated system or the fragment hydrogen bonded with the deprotonated IH ring for the deprotonated chain rotates and the system is recovering. The detailed conduction mechanism need to be verified experimentally.

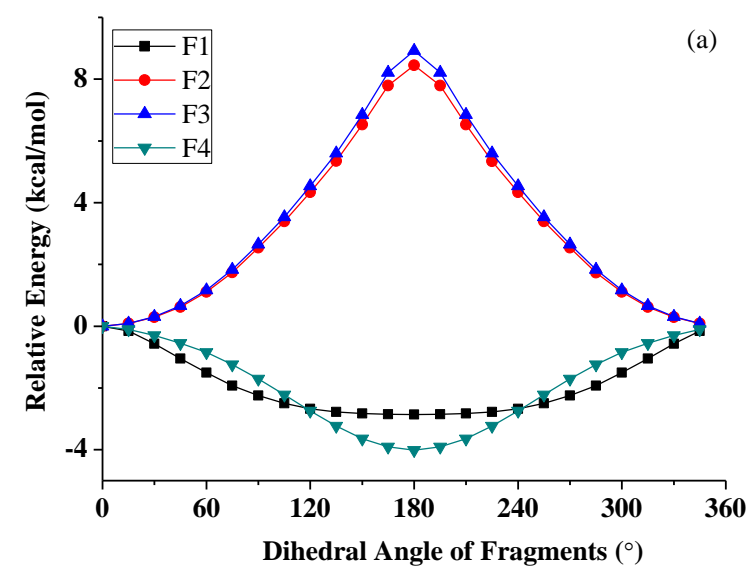



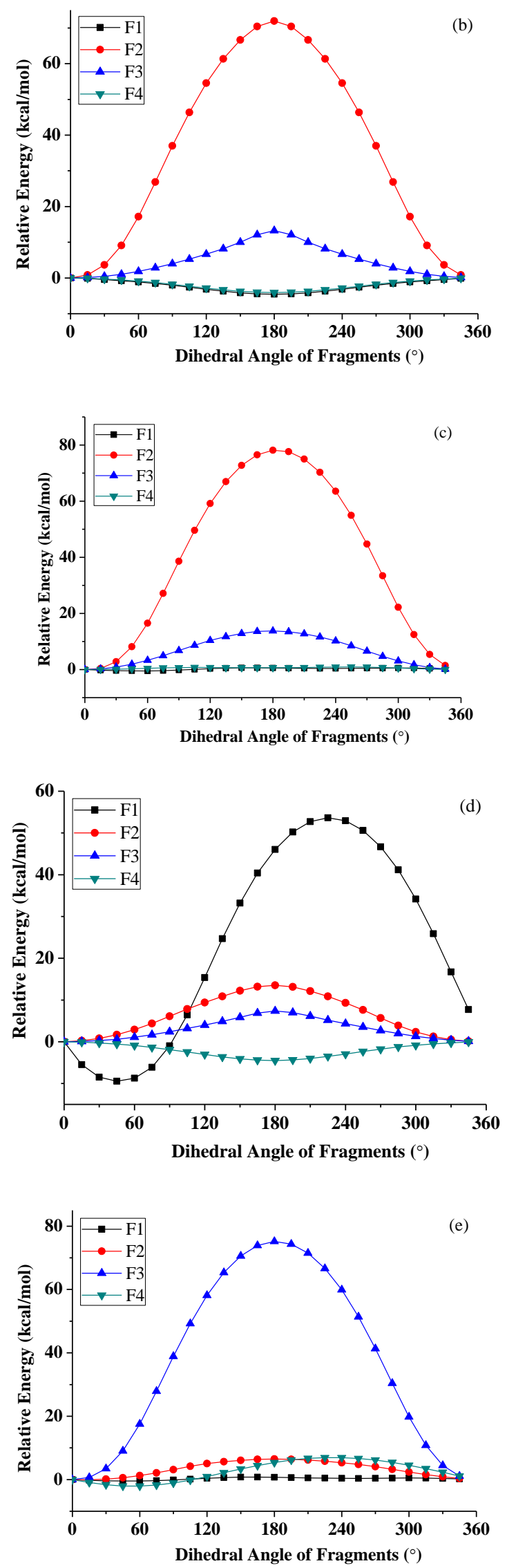

Figure7. The proton transfer potential energy surfaces along with the rotation of mediated imidazole molecules. (a) (e) denote the neutral, oxidized, reduced, protonated, and deprotonated chains, respectively. F1 F4 refer to the imidazole fragments in the chain from left to right, respectively 


\subsection{Binding Energy}

Binding energy $\left(E_{\mathrm{b}}\right)$ denotes the energy released when the components combines together or the energy required to disassemble a system into separate parts. For neutral system, the $E_{\mathrm{b}}$ of IH mediated chain is higher than the other two (Table 4), demonstrating the stronger NH...H interaction between $\mathrm{IH}$ fragments. Upon oxidation, the $E_{\mathrm{b}} \mathrm{S}$ of these chains increase distinctly for the enhancement of electrostatic interaction between terminal IH and mediated molecules. For IH and ammonia mediated systems, the variation is more significant owing to the proton transfer from left terminal IH fragment to the middle bridging molecules. The $E_{\mathrm{b}}$ increases also distinctly upon reduction for these three chains due to the strengthened electrostatic interaction. The water mediated system is the most stable one among the reduced chains owing to its distinct structural rearrangement. The $E_{\mathrm{b}}$ value of both protonated and deprotonated systems, represented in Table 4, is larger by several $\mathrm{kcal} / \mathrm{mol}$ than the corresponding neutral chains, indicating that the stability of these systems is enhanced moderately.

The larger the $E_{\mathrm{b}}$ is, the more stable the system is. Then, the subsequent reaction is more difficult. Therefore, it is expected that the initial reaction of IH mediated system during the conduction process should not be oxidation by electron detachment. The situation is similar to the ammonia mediated system. The $E_{\mathrm{b}}$ of ammonia mediated system is the least among these systems, therefore, it should be better in conductivity than the other two.

Table4. The binding energy $\left(E_{b}\right)^{a}$ for the imidazole, water, and ammonia mediated chains

\begin{tabular}{|c|c|c|c|c|}
\hline IH-2IH-IH & IH-2IH-IH $^{+}$ & IH-2IH-IH & HIH-2IH-IH $^{+}$ & IH-2IH-I \\
\hline 11.1 & 28.7 & 18.6 & 16.5 & 14.9 \\
\hline IH-4W-IH & IH-4W-IH $^{+}$ & IH-4W-IH' & HIH-4W-IH ${ }^{+}$ & IH-4W-I' \\
\hline 10.5 & 16.1 & 19.6 & 13.8 & 14.1 \\
\hline IH-4A-IH & IH-4A-IH ${ }^{+}$ & IH-4A-IH' & HIH-4A-IH $^{+}$ & IH-4A-I' \\
\hline 6.4 & 25.9 & 10.4 & 11.9 & 6.9 \\
\hline
\end{tabular}

\footnotetext{
${ }^{a}$ The unit is in kcal/mol.
}

\section{CONCLUSiON}

The hydrogen bonded imidazole, water, and ammonia mediated systems are explored employing the DFT B3LYP/6-311++G(d, p) approach, with a special emphasis on the electronic and protonic effect. Both oxidation and reduction can lead to the proton transfer spontaneously for the imidazole mediated system. It is not observed upon either protonation or deprotonation. Proton also transfers spontaneously upon oxidation in ammonia mediated chain. The flexibility of water and ammonia mediated systems is larger as compared with that of imidazole mediated chain. The typical IR spectra of NH...N hydrogen bond varies distinctly upon both electron and proton attachment/detachment. NMR parameters (both the chemical shift of $\mathrm{H}$ and the spin-spin coupling constant of $\mathrm{NH}$ ) are employed as the indexes for proton transfer, indicated by their significant variation. The potential energy surface demonstrates that the fragment rotation of those bearing excess proton or hydrogen bonded with the deprotonated imidazole ring is forbidden. The initial step for the proton conduction mechanism of imidazole chain should not be oxidation. It is expected that the ammonia media is better in conductivity as compared to water and imidazole.

\section{ACKNOWLEDGMENT}

This work is supported by National Natural Science Foundation of China (Grant No. 21203227, 21103080), Natural Science Foundation of Shandong Province (Grant No. ZR2016BM33), and the Research Foundation for Talented Scholars of the Qingdao Agricultural University (No. 6631113335). The numerical calculations in this paper have been done on the supercomputing system in the Supercomputing Center of University of Science and Technology of China. 


\section{REFERENCES}

${ }^{1}$ Daycock, J. T.; Jones, G. P.; Evans, J. R. N.; Thomas, J. M. Rotation of Imidazole in the Solid State and Its Significance in Deciding the Nature of Charge Migration in Biological Materials. Nature, 1968, $218,672-673$.

${ }^{2}$ Wolkenberg, S. E.; Wisnoski, D. D.; Leister, W. H.; Wang, Y.; Zhao, Z.; Lindsley, C. W. Efficient synthesis of Imidazoles from Aldehydes and 1,-Diketones Using Microwave Irradiation. Org. Lett. 2004, 6, 1453-1456.

${ }^{3}$ De Luca. L. Naturally Occurring and Synthetic Imidazoles: Their Chemistry and Their Biological Activities. Curr. Med. Chem. 2006, 13, 1-23.

${ }^{4}$ Kawada, A.; McGhie, A. R.; Labes, M. M. Protonic Conductivity in Imidazole Single Crystal J. Chem. Phys. 1970, 52, 3121-3125.

${ }^{5}$ Horiuchi, S.; Kagawa, F.; Hatahara, K.; Kobayashi, K.; Kumai, R.; Murakami, Y.; Tokura, Y. AboveRoom-Temperature Ferroelectricity and Antiferroelectricity in Benzimidazoles. Nat. Comm. 2012, 3, 1308-1314.

${ }^{6}$ Ji, C.-M.; Chen, T.-L.; Sun, Z.-H.; Ge, Y.; Lin, W.-X.; Luo, J.-H.; Shi, Q.; Hong, M.-C. Bulk Crystal Growth and Characterization of Imidazolium L-tartrate (IMLT): A Novel Organic Nonlinear Optical Material with a High Laser-Induced Damage Threshold. Cryst. Eng. Comm. 2013, 15, 2157-2162.

${ }^{7}$ Kreuer, K.-D.; Paddison, S. J.; Spohr, E.; Schuster, M. Transport in Proton Conductors for Fuel-Cell Applications: Simulations, Elementary Reactions, and Phenomenology. Chem. Rev. 2004, 104, 46374678.

${ }^{8}$ Perchard, C.; Novak, A. Far-Infrared Spectra and Hydrogen-Bond Frequencies of Imidazole. J. Chem. Phys. 1968, 48, 3079-3084.

${ }^{9}$ Kreuer, K. D.; Fuchs, A.; Ise, M.; Spaeth, M.; Maier, J. Imidazole and Pyrazole-Based Proton Conducting Polymers and Liquids. Electrochim. Acta 1998, 43, 1281-1288.

${ }^{10}$ Pogorzelec-Glaser, K.; Rachocki, A.; Lawniczak, P.; Lapinski, A.; Tritt-Goc, J. Synthesis and Characterization of a New Proton-Conducting Material Based on Imidazole and Selenic Acid. Solid State Ionics 2012, 227, 96-101.

${ }^{11}$ Jarumaneeroj, C.; Tashiro, K.; Chirachanchai, S. Molecular Mobility of Imidazoles in Molten State as a Key Factor to Enhance Proton Conductivity. J. Power Sources 2014, 249, 185-192.

${ }^{12} \mathrm{Pu}, \mathrm{H}$.; Wang, D. Studies on Proton Conductivity of Polyimide/ $\mathrm{H}_{3} \mathrm{PO}_{4} /$ Imidazole Blends. Electrochim. Acta 2006, 51, 5612-5617.

${ }^{13}$ Hickman, B. S.; Mascal, M.; Titman, J. J.; Wood, I. G. Protonic Conduction in Imidazole: A Solid-State ${ }^{15}$ N NMR Study. J. Am. Chem. Soc. 1999, 121, 11486-11490.

${ }^{14}$ Mangiatordi, G. F.; Butera, V.; Russo, N.; Laage, D.; Adamo, C. Charge Transport in Poly-Imidazole Membranes: A Fresh Appraisal of the Grotthuss Mechanism. Phys. Chem. Chem. Phys. 2012, 14, 10910-10918.

${ }^{15}$ Mangiatordi, G. F.; Laage, D.; Adamo, C. Backbone Effects on the Charge Transport in Poly-Imidazole Membranes: A Theoretical Study. J. Mater. Chem. A 2013, 1, 7751-7759.

${ }^{16}$ Deng, W.-Q.; Molinero, V.; Goddard, W. A. Fluorinated Imidazoles as Proton Carriers for Water-Free Fuel Cell Membranes. J. Am. Chem. Soc. 2004, 126, 15644-15645.

${ }^{17}$ Vilciauskas, L.; Tuckerman, M. E.; Bester, G.; Paddison, S. J.; Kreuer, K. D. The Mechanism of Proton Conduction in Phosphoric Acid. Nat. Chem. 2012, 4, 461-466.

${ }^{18}$ Iannuzzi, M.; Parrinello, M. Proton Transfer in Heterocycle Crystals. Phys. Rev. Lett. 2004, 93, No. 025901.

${ }^{19}$ Shaik, M. S.; Liem, S. Y.; Yuan, Y.; Popelier, P. L. A. Simulation of Liquid Imidazole Using a HighRank Quantum Topological Electrostatic Potential. Phys. Chem. Chem. Phys. 2010, 12, 1504015055.

${ }^{20}$ Scheiner, S.; Yi, M. Proton Transfer Properties of Imidazole. J. Phys. Chem. 1996, 100, 9235-9241.

${ }^{21}$ Munch, W.; Kreuer, K. D.; Silvestri, W.; Maier, J.; Seifert, G. The Diffusion Mechanism of an Excess Proton in Imidazole Molecule Chains: First Results of an Ab Initio Molecular Dynamics Study. Solid State Ionics 2001, 145, 437-443.

${ }^{22}$ Chen, H.; Yan, T.; Voth, G. A. A. Computer Simulation Model for Proton Transport in Liquid Imidazole. J. Phys. Chem. A 2009, 113, 4507-4517. 
${ }^{23}$ Nimmanpipug, P.; Yana, J.; Lee, V. S.; Vannarat, S.; Chirachanchai, S.; Tashiro, K. Density Functional Molecular Dynamics Simulations Investigation of Proton Transfer and Inter-Molecular Reorientation under External Electrostatic Field Perturbation: Case Studies for Water and Imidazole Systems. J. Power Sources 2013, 229, 141-148.

24 Yan, S.; Bu, Y.; Cao, Z.; Li, P. Coupling Character between Imidazole and Imidazole Cation: Implication for the Coupling Modes of Biomolecular Residues. J. Phys. Chem. A 2004, 108 70387049.

${ }^{25}$ Yan, S.; Bu, Y. Alteration of Imidazole Dimer on Oxidation or Water Ligation. J. Phys. Chem. B 2004, 108, 13874-13881.

${ }^{26}$ Yan, S.; Bu, Y. Coupling Properties of Imidazole Dimer Radical Cation Assisted by Embedded Water Molecule: Toward Understanding of Interaction Character of Hydrogen-Bonded Histidine ResidueChains. J. Chem. Phys. 2005, 122, 184324-184331.

${ }^{27}$ Yan, S.; Bu, Y.; Cukier, R. I. Electron Bridging Dihydrogen Bond in the Imidazole-Contained Anion Derivatives. J. Chem. Phys. 2006, 124, 124314-124323.

${ }^{28}$ Yan, S.; Bu, Y. Properties and Isomerization Mechanism of the Singlet State Imidazole-Imidazolium System. J. Mol. Struct. (Theochem) 2005, 1-8.

${ }^{29}$ Yan, S.; Bu, Y.; Li, P. Electronic Effect on Protonated Hydrogen-Bonded Imidazole Trimer and Corresponding Derivatives Cationized by Alkali Metals $\left(\mathrm{Li}^{+}, \mathrm{Na}^{+}\right.$, and $\left.\mathrm{K}^{+}\right) \mathrm{J}$. Chem. Phys. 2005, 122, 054311-054320.

${ }^{30}$ Yan, S.; Zhang, L.; Cukier, R. I.; Bu, Y. Exploration on Regulating Factors for Proton Transfer along Hydrogen-Bonded Water Chains. ChemPhysChem 2007, 8, 944-954.

${ }^{31}$ Sharma, B. B.; Verma, A. K.; Thomas, S.; Murli, C.; Sarma, S. M. Hydrogen Bonds and Ionic Forms versus Polymerization of Imidazole at High Pressures. J. Phys. Chem. B 2015, 119, 372-378.

${ }^{32}$ Kumar, M.; Venkatnathan, A. Quantum Chemistry Study of Proton Transport in Imidazole Chains. J. Phys. Chem. B 2015, 119, 3213-3222.

33 O'Malley, P. J.; Collins, S. J. Density functional studies of free redicals: Accurate geometry and hyperfine coupling prediction for semiquinone anions. Chem. Phys. Lett. 1996, 259,296-300.

${ }^{34} \mathrm{O}$ 'Malley, P. J. ${ }^{1} \mathrm{H},{ }^{13} \mathrm{C}$ and ${ }^{17} \mathrm{O}$ principal hyperfine tensor determination for the p-benzosemiquinone anion radical using hybrid density functional methods. Chem. Phys. Lett. 1996, 262, 797-800.

${ }^{35}$ O’Malley, P. J. Hybrid density functional study of the p-Benzosemiquinone anion radical: The influence of hydrogen bonding on geometry and hyperfine couplings. J. Phys. Chem. A 1997, 101, 6334-6338.

${ }^{36}$ O'Malley, P. J. Effect of hydrogen bonding on the spin density distribution and hyperfine couplings of the p-Benzosemiquinone anion radical in alcohol solvents: A hybrid density functional study. J. Phys. Chem. A 1997, 101, 9813-9817.

${ }^{37}$ O'Malley, P. J. B3LYP, hybrid density functional studies of the durosemiquinone radical: The effect of symmetrical and asymmetrical hydrogen bonding on spin densities and hyperfine couplings. J. Phys. Chem. A 1998, 102, 248-253.

${ }^{38}$ Adamo, C.; Barone, V. In Recent Development in Density Functional Methods; Chong, D. P., Ed.; World Scientific Publishing: Singapore, 1997; Part II.

39 Himo, F.; Graslund, A.; Eriksson, L. E. Density functional calculations on model tyrosyl radicals. Biophys. J. 1997, 72, 1556-1567.

${ }^{40}$ Qin, Y.; Wheeler, R. A. Density-functional methods give accurate vibrational frequencies and spin densities for phenoxyl radical J. Chem. Phys. 1995, 102, 1689-1698.

${ }^{41}$ Ciobanu, C. V.; Ojamäe, L.; Shavitt, I.; Singer, S. J. Structure and vibrational spectra of $\mathrm{H}^{+}\left(\mathrm{H}_{2} \mathrm{O}\right)_{8}$ : Is the excess proton in a symmetrical hydrogen bond? J. Chem. Phys. 2000, 113, 5321-5330.

${ }^{42}$ Christie, R. A.; Jordan, K. D. Theoretical investigation of the $\mathrm{H}_{3} \mathrm{O}^{+}\left(\mathrm{H}_{2} \mathrm{O}\right)_{4}$ cluster J. Phys. Chem. A 2001, 105, 7551-7558.

${ }^{43}$ Mella, M.; Kuo, J. L.; Clary, D. C.; Klein, M. L. Nuclear quantum effects on the structure and energetics of $\left(\mathrm{H}_{2} \mathrm{O}\right)_{6} \mathrm{H}^{+}$Phys. Chem. Chem. Phys. 2005, 7, 2324-2332.

${ }^{44}$ Sychrovský, V.; Gräefenstein, J.; Cremer, D. Nuclear magnetic resonance spin-spin coupling constants from coupled perturbed density functional theory J. Chem. Phys. 2000, 113, 3530-3547.

${ }^{45}$ Helgaker, T.; Watson, M.; Handy, N. C. Analytical calculation of nuclear magnetic resonance indirect spin-spin coupling constants at the generalized gradient approximation and hybrid levels of densityfunctional theory J. Chem. Phys. 2000, 113, 9402-9409. 
${ }^{46}$ Sychrovský, V.; Šponer, J.; Hobza, P. Theoretical calculation of the NMR spin-spin coupling constants and the NMR shifts allow distinguishability between the specific direct and the water-mediated binding of a divalent metal cation to guanine. J. Am. Chem. Soc. 2004, 126, 663-672.

${ }^{47}$ Zhu, W.-L.; Puah, C. M.; Tan, X.-J.; Jiang, H.-L.; Chen, K.-X. Quantum chemistry investigation on the dihydrogen bond between silicane and ammonium. J. Phys. Chem. A 2001, 105, 426-431.

${ }^{48}$ Frisch M. J.; Trucks G. W.; Schlegel H. B.; Scuseria G. E.; Robb M. A.; Cheeseman J. R.; Scalmani G.; Barone V.; Mennucci B.; Petersson G. A.; Nakatsuji H.; Caricato M.; Li X.; Hratchian H. P.; Izmaylov A. F.; Bloino J.; Zheng G.; Sonnenberg J. L.; Hada M.; Ehara M.; Toyota K.; Fukuda R.; Hasegawa J.; Ishida M.; Nakajima T.; Honda Y.; Kitao O.; Nakai H.; Vreven T.; Montgomery J. A.; Peralta Jr. J. E.; Ogliaro F.; Bearpark M.; Heyd J. J.; Brothers E.; Kudin K N.; Staroverov V. N.; Keith T.; Kobayashi R.; Normand J.; Raghavachari K.; Rendell A.; Burant J. C.; Iyengar S. S.; Tomasi J.; Cossi M.; Rega N.; Millam J. M.; Klene M.; Knox J. E.; Cross J. B.; Bakken V.; Adamo C.; Jaramillo J.; Gomperts R.; Stratmann R. E.; Yazyev O.; Austin A. J.; Cammi R.; Pomelli C.; Ochterski J. W.; Martin R. L.; Morokuma K.; Zakrzewski V. G.; Voth G. A.; Salvador P.; Dannenberg J. J.; Dapprich S.; Daniels A. D.; Farkas O.; Foresman J. B.; Ortiz J. V.; Cioslowski J.; Fox D. J. Gaussian; Gaussian 09; Revision B.01; Gaussian; Inc.: Wallingford CT: 2010.

${ }^{49}$ Miertus, S.; Scrocco, E.; Tomsi, J. Electrostatic interaction of a solute with a continuum. A direct utilization of $A b$ initio molecular potentials for the prevision of solvent effects. Chem. Phys. 1981, $55,117-.129$

${ }^{50}$ Miertus, S.; Tomasi, J. Approximate evaluations of the electrostatic free energy and internal energy changes in solution processes. Chem. Phys. 1982, 65, 239-245.

51 Cossi, M.; Barone, V.; Cammi, R.; Tomasi, J. Ab initio study of solvated molecules: a new implementation of the polarizable continuum model. Chem. Phys. Lett. 1996, 255, 327-335.

${ }^{52}$ Cammi, R.; Mennucci, B.; Tomasi, J. Solvent effects on linear and nonlinear optical properties of donoracceptor polyenes: Investigation of electronic and vibrational components in terms of structure and charge distribution changes. J. Am. Chem. Soc. 1998, 120, 8834-8847.

${ }^{53}$ Cammi, R. The Hartree-Fock calculation of the magnetic properties of molecular solutes. J. Chem. Phys. 1998, 109, 3185-3196.

${ }^{54}$ Mennucci, B.; Martinez, J. M.; Tomasi, J. Solvent effects on nuclear shieldings: Continuum or discrete solvation models to treat hydrogen bond and polarity effects? J. Phys. Chem. A 2001, 105, 72877296.

${ }^{55}$ Kobayashi, C.; Iwahashi, K.; Saito, S.; Ohmine, I. Dynamics of proton attachment to water cluster: Proton transfer, evaporation, and relaxation. J. Chem. Phys. 1996, 105, 6358-6366.

${ }^{56}$ Catalan, J.; Carlos del Valle, J.; Kasha, M. Resolution of concerted versus sequential mechanisms in photo-induced double-proton transfer reaction in 7-azaindole H-bonded dimer. Proc. Natl. Acad. Sci. USA 1996, 96, 8338-8343.

${ }^{57}$ Kohanoff, J.; Koval, S.; Estrin, D. A.; Laria, D.; Abashkin, Y. Concertedness and solvent effects in multiple proton transfer reactions: The formic acid dimer in solution. J. Chem. Phys. 2000, 112, 9498-9508.

${ }^{58}$ Park, S.-Y.; Kim, Y.; Lee, J. Y.; Jang, D.-J. Ground-state proton transport along a blended-alcohol chain: Accelerated by accumulated proton-donating ability. J. Phys. Chem. B 2012, 116, 10915-10921.

${ }^{59}$ Iannuzzi, M. Proton transfer in imidazole-based molecular crystals. J. Chem. Phys. 2006, 124, 204710204719.

Citation: S. Yan, "Effect of Electron and Proton on Hydrogen-Bonded Imidazole Chains", International Journal of Advanced Research in Chemical Science (IJARCS), vol. 4, no. 7, pp. 16-31, 2017. http://dx.doi.org/ 10.20431/2349-0403. 0407004

Copyright: (C) 2017 Authors. This is an open-access article distributed under the terms of the Creative Commons Attribution License, which permits unrestricted use, distribution, and reproduction in any medium, provided the original author and source are credited. 